\title{
Research Paper: Relationship Between Talent Manage- ment and Organizational Commitment in Midwives Working in Iran University of Medical Sciences
}

\author{
Masoomeh Kheirkhah $^{1}$, Vahideh Akbarpouran ${ }^{1 *}$, Hamid Haqhani ${ }^{2}$ \\ 1. Department of Midwifery, School of Nursing \& Midwifery, Iran University of Medical Sciences, Tehran, Iran. \\ 2. Department of Biostatistics, School of Public Health, Iran University of Medical Sciences, Tehran, Iran.
}

Citation: Kheirkhah, M., Akbarpouran V., Haqhani H. 2016. Relationship Between Talent Management and Organizational Commitment in Midwives Working in Iran University of Medical Sciences. Journal of Client-Centered Nursing Care, 2(3), pp. 145-152. https://doi.org/10.32598/ jecnc.2.3.145

: https://doi.org/10.32598/jccnc.2.3.145

Article info:

Received: 25 Dec. 2015

Accepted: 10 May. 2016
Keywords:

Talent management, Organizational commitment, Midwives

\begin{abstract}
A B S T RA C T
Background: One of the important challenges to health service policy makers is conservation of human force. Shortage of human forces required for health and treatment services causes harm to quality of services. The present research aimed at determining the relationship between talent management and organizational commitment in midwives working in hospitals affiliated to Iran University of Medical Sciences.

Methods: This research was a descriptive cross-sectional study. Because the sample size was equal with the statistical population, all midwives working in hospitals affiliated to Iran University of Medical Sciences participated in it (177 midwives). The total count sampling method was used and duration of sampling lasted two months (from April 2 to May 31). Information was collected using Arabpour and Nikpour's talent management researcher-made questionnaire and Allen-Meyer's [24-item] Organizational Commitment Questionnaire. The obtained data were analyzed using descriptive statistics, analysis of variance, Pearson's correlation and Independent $\mathrm{t}$ test by SPSS (Version 16).
\end{abstract}

Results: Talent management was in a higher-than-average condition with a mean score of 3.05 . Dimensions of talent development (3.37) and talent conservation (2.73) had the highest and lowest mean scores, respectively. The score of organizational commitment of midwives was 101, and the affective commitment dimension had the highest mean value (35) among others. Pearson's correlation coefficient for the correlation between talent management (and its dimensions) and organizational commitment (and its dimensions) revealed a statistically significant relationship $(\mathrm{P}<0.001, \mathrm{r}=0.48)$.

Conclusion: Considering the correlation between talent management and organizational commitment, hospital managers can improve midwives' commitment using new management methods to encourage growth of human force talents and capabilities.

\section{* Corresponding Author:}




\section{Background}

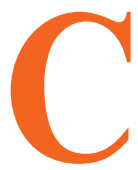

onservation of human forces is an important challenge to health service policy makers. Performance and quality of a health system depends on the quality and motivation of its human resources, which are considered the main component of patient care. Lack of concern for human resource management problems prevents improvement of health care services provided to patients (Aliyu et al. 2014). Dissatisfaction and increased turnover in health and treatment service professions harms quality of services and results in a decrease in efficiency and health care quality, imposes overload on other employees, and leads to low spirit and motivation among employees (Al-Hassan 2014).

In today's competitive world, human resources are significantly important to organizations and turnover of talented employees are a threat to organizational growth. Moreover, with the increase in selection and hiring processes, additional costs are imposed on organizations. Through proper management and generation of motivation in employees, it is possible to avoid adverse effects of turnover. Committed employees are considered an organization's valuable assets, whose high levels of commitment bring about increased job satisfaction, motivation, performance and creativity and reduce absence and turnover (Mosadeghrad, Ferlie, \& Rosenberg 2008). With higher levels of commitment, employees offer higher levels of performance in an organization (Nehrir et al. 2010).

Considering the special role of human resources in achievement of goals and increased production and effectiveness, employees' commitment to organizational goals can be the key to organizations' success (Mosadeghrad, Ferlie, \& Rosenberg 2008). Managers and their leadership styles considerably influence the use of financial and human resources and success of organizations. Few studies have been conducted on the new methods of management and advantages of supporting employees (Lesly Onnis, 2014). Managers' leadership style contributes to the growth of employees' organizational commitment and quality of services (Mosadeghrad \& Ferdosi 2013). Organizations all over the world are confronted with numerous problems in hiring and conserving the talents required for attainment of organizational goals, and the number of these challenges is higher for beginners (Amiri et al. 2014). Talent management is one of the most vital challenges of human resources that organizations will face in future decades. Organization managers allocate more than $20 \%$ of their time to activities associated with this kind of management (Collings, Mcdonnell \& Scullion 2009).
Complete implementation of talent management corresponds to the mission, vision, and values of organizations (Tajuddin \& Kamaruddin 2014). Talent management is among the new management methods, which have shaped evolution of human capital management and have overcome weaknesses of traditional approaches. This aproach can be used along with human resource management to successfully discover and conserve talents (Taleghani et al. 2014). Talent management is a continuous process, which should be an integral part of organizational culture. This kind of management can improve organizational learning, too (Kheirkhah, Akbarpouran \& Haqani 2016).

Because no prior study has been conducted in hospitals and among midwives, the present research aimed to study the relationship between talent management and organizational commitment of midwives in hospitals of Iran University of Medical Sciences in 2016.

\section{Materials \& Methods}

\section{Study type}

It was a descriptive cross-sectional study that was conducted on midwives working in the maternity ward, NICU (Neonatal Intensive Care Unit), IVF (In Vitro Fertilization), women surgery ward, and nursing offices of hospitals affiliated to Iran University of Medical Sciences in 2016. Because the study examined the views of midwives in the management and organizational commitment from, all levels of working midwives in the centers of universities were sampled.

\section{Method}

AfterobtainingpermitNo.IR.IUMS.REC.1394.9211373210 from the university Ethics Committee and a letter of introduction from the Research Deputy, the researcher referred to hospitals affiliated to Iran University of Medical Sciences and after introducing herself, expressed research objectives, and explained the research significance. Then the questionnaires were provided to the qualified participants.

\section{Research participants}

The total count sampling method was used to include all of the midwives with a minimum degree of midwifery associate degree and 6 months of experience. The inclusion criterion for the management section was one year (or more than a year) of experience with management in a related unit. If the existing management lacked the adequate experience, questionnaires would be completed based on the management type by the former manager. 


\section{Data instruments}

In this research, three questionnaires, namely the demographic characteristics questionnaire, talent management (for assessment of the talent management system of organizations), and Allen-Meyer's Organizational Commitment questionnaire were used. To assess talent management, Arabpour and Nikpor 25-item researcher-made questionnaire was used. Dimensions of the questionnaire consisted of talent absorption, talent conservation, and talent development. Items of this questionnaire were ranked based on a 5-point Likert-type scale from "completely disagreed" to "completely agreed" and the options were scored from 1 to 5 . A number of 9, 6, and 10 questions were designed for the talent absorption, talent conservation, and talent development dimensions, respectively. The questionnaire results were interpreted using the mean score values. To this end, a mean talent management score of less than 3 was considered below average and the score of 3 and higher was considered higher than average (Arabpour \& Nikpour 2014). Validity of the questionnaire was assessed using the content and face validity assessment tests, and its reliability was confirmed with a Cronbach $\alpha$ coefficient of 0.82 . The calculated Cronbach $\alpha$ coefficients for absorption, conservation, and development of talents were $0.70,0.73$, and 0.87 , respectively.

Allen-Meyer's 24-item organizational commitment questionnaire was used to measure organizational commitment of employees based on a 7-point Likert-type scale (completely disagreed, disagreed, almost disagreed, no idea, almost agreed, agreed, completely agreed) and items were scored from 1 to 7 . The first, second, and third 8 questions tested the affective, continuance, and normative dimensions of commitment, respectively. Questions 4, 5, 6, 8, 9, 18, 19, 21, 24 were ranked in a reverse order (Allen \& Meyer 1990). This questionnaire has been translated into Persian and its validity and reliability were tested (Saatchi, Kamkari \& Askarian 2010).

Validity of this questionnaire was tested using the content and face validity method. The Cronbach $\alpha$ coefficients obtained in assessing reliability of the organizational commitment and its dimensions (affective, continuance, and normative) of the questionnaire were 0.80 , $0.78,0.81$, and 0.70 , respectively. The minimum and maximum scores were 24 and 168, respectively. A higher score showed a high level of organizational commitment.

\section{Data analysis}

After collecting the questionnaires, the obtained data were analyzed using descriptive statistics, analysis of variance, Pearson's correlation and Independent t test by SPSS version 16.

\section{Results}

Concerning demographic characteristics, 86(48.6\%) participants were below 29 years old, 143(80.8\%) had bachelor's degree, $83(46.8 \%$ ) were temporary employees, and $65(36.7 \%)$ were officially employed. Moreover, 101 participants had an experience of less than 6 years. Demographic characteristics information is shown in Table 1.

The numerical indicators of talent management and its dimensions are shown in Table 2.

According to Table 2, 57.6\% of participants reported a talent management status of higher than average. The mean (SD) score of talent management was 3.05(0.68). The talent development dimension (with a mean (SD) score of $3.37(0.85)$ had the highest mean score, whereas the talent conservation dimension with a mean (SD) score of 2.73(0.92) had the lowest mean score.

The mean (SD) score of organizational commitment of working midwives was 101(20.06). The affective commitment dimension with a mean (SD) score of 35 (9.56) had the highest mean, whereas normative commitment with a mean (SD) score of 31 (7.28) had the lowest mean score (Table 3).

Results of the Pearson's correlation test (Table 4) revealed a statistically significant relationship between talent management and organizational commitment $(\mathrm{P}<0.001, \mathrm{r}=0.48)$. The highest level of relationship between organizational commitment dimensions with talent management was observed between affective, normative, and continuance commitment dimensions ( $\mathrm{P}$ $<0.001)$. And the highest level of relationship between dimensions of talent management with organizational commitment was observed between talent development, talent conservation and talent absorption dimensions, in the mentioned order $(\mathrm{P}<0.001)$.

\section{Discussion}

Considering the importance of human resources, this study aimed to investigate the relationship between talent management and organizational commitment in midwives working in hospitals affiliated to Iran University of Medical Sciences. Analysis of talent management among midwifery managers suggest that the mean scores of talent absorption and conservation dimensions were lower than average. 
Table 1. Demographic characteristics information for the research participants

\begin{tabular}{|c|c|c|c|}
\hline Variable & Sub Group & No. & $\%$ \\
\hline \multirow{5}{*}{ Age, y } & Lower than 29 & 86 & 48.6 \\
\hline & $30-39$ & 31 & 17.5 \\
\hline & & 36 & 203 \\
\hline & 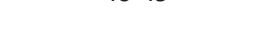 & & \\
\hline & More than 50 & 24 & 13.6 \\
\hline \multirow{3}{*}{ Marital status } & Single & 85 & 48 \\
\hline & & & \\
\hline & Married & 92 & 52 \\
\hline \multirow{3}{*}{ Educational level } & Associate degree & 4 & 2.3 \\
\hline & Bachelor's degree & 143 & 80.8 \\
\hline & Master's degree & 30 & 16.9 \\
\hline \multirow{3}{*}{ Employment } & Official employee & 65 & 36.7 \\
\hline & Temporary employee & 83 & 46.8 \\
\hline & Under contract & 29 & 16.5 \\
\hline \multirow{3}{*}{ Organizational position } & Midwife & 167 & 94.3 \\
\hline & & & \\
\hline & In-charge midwife & 10 & 5.7 \\
\hline \multirow{5}{*}{ Work experience, y } & Lower than 6 & 101 & 57.1 \\
\hline & $6-12$ & 14 & 7.9 \\
\hline & $13-18$ & 11 & 6.2 \\
\hline & $19-24$ & 26 & 14.7 \\
\hline & More than 25 & 25 & 14.1 \\
\hline \multirow{5}{*}{ Work experience in current workplace } & Lower than 6 & 128 & 72.3 \\
\hline & $6-12$ & 17 & 9.6 \\
\hline & $13-18$ & 15 & 8.5 \\
\hline & $19-24$ & 9 & 5.1 \\
\hline & More than 25 & 8 & 4.5 \\
\hline Total & & 177 & 100 \\
\hline
\end{tabular}

Based on the research by Nopasand Asil et al. (2013), the talent conservation and development had the highest and lowest mean scores, respectively, which does not comply with results of this research. This difference in results can be ascribed to the difference between the research environments, populations, and jobs of participants. In the research by Nopasand Asil et al. (2013), all technical and administrative employees completed the questionnaires.
Considering the fields of operation of the participants, the management greatly valued payment of wages and benefits based on competencies of employees and realization of organizational goals, yet it failed to value training courses. Since in hospitals midwives are involved in the health of mothers and neonates, the management has tried to improve knowledge and competency of its employees, but salaries are not paid in accordance with competency 
Table 2. Talent management and its dimensions of the research participants (2016)

\begin{tabular}{cccccc}
\hline $\begin{array}{c}\text { Talent Management and } \\
\text { Dimensions }\end{array}$ & $\begin{array}{c}\text { Below Average } \\
\text { (Less Than 3), No. } \\
(\%)\end{array}$ & $\begin{array}{c}\text { More Than Average } \\
\text { ( } \begin{array}{c}\text { and Higher), } \\
\text { No. (\%) }\end{array}\end{array}$ & Mean Score & SD & $\begin{array}{c}\text { Range of } \\
\text { Variations }\end{array}$ \\
\hline Talent management & $75(42.4 \%)$ & $102(57.6 \%)$ & 3.05 & 0.68 & $1.1-4.6$ \\
\hline Talent absorption & $85(48 \%)$ & $92(52 \%)$ & 2.91 & 0.66 & $1-5$ \\
\hline Talent conservation & $96(54.2 \%)$ & $81(45.8 \%)$ & 2.73 & 0.92 & $1-5$ \\
\hline Talent development & $48(27.1 \%)$ & $129(72.9 \%)$ & 3.37 & 0.85 & $1-5$ \\
\hline
\end{tabular}

Client-Centered Nursing Care

Table 3. Organizational commitment and dimensions of study participants (2016)

\begin{tabular}{ccccc}
\hline Organizational Commitment and Dimensions & Minimum & Maximum & Mean Score & SD \\
\hline Organizational commitment (168-24) & 44 & 149 & 101 & 20.06 \\
Affective dimension (56-8) & 12 & 56 & 35 & 9.56 \\
Continuance dimension (56-8) & 8 & 55 & 31 & 10.20 \\
Normative dimension (56-8) & 10 & 51 & 7.28 \\
\hline
\end{tabular}

Client-Centered Nursing Care

Table 4. The relationship between talent management (and dimensions) with organizational commitment (and dimensions) in the study participants (2016)

\begin{tabular}{rcccc}
\hline Organizational Commitment & $\begin{array}{c}\text { Organizational } \\
\text { Commitment }\end{array}$ & $\begin{array}{c}\text { Affective } \\
\text { Commitment }\end{array}$ & $\begin{array}{c}\text { Continuance } \\
\text { Commitment }\end{array}$ & $\begin{array}{c}\text { Normative } \\
\text { Commitment }\end{array}$ \\
Talent Management & $r=0.48$ & $r=0.54$ & $r=0.16$ & $r=0.37$ \\
Talent management & $P<0.001$ & $P<0.001$ & $P<0.001$ & $P<0.001$ \\
Talent absorption & $r=0.36$ & $r=0.38$ & $r=0.13$ & $r=0.30$ \\
Talent conservation & $P<0.001$ & $P<0.001$ & $P<0.001$ & $r=0.001$ \\
Talent development & $r=0.42$ & $r=0.47$ & $r=0.14$ & $P<0.001$ \\
\hline
\end{tabular}

Client-Centered Nursing Care

of employees. Moreover, they performed poorly with regard to the talent absorption and conservation dimensions.

In the investigation by Salehi Kurd Abadi et al. (2015), all three dimensions of talent management were in a satisfactory condition. Results of this research only comply with our findings concerning development of talents. The reason for the lack of compliance between the results can be ascribed to the difference between two research settings. Environments such as justice departments try harder to absorb and conserve employees due to their high number of clients, whereas the health and treatment centers employ temporary and $\mathrm{K}$ factor forces to meet their needs.

Although this strategy effectively and successfully meets the system's need for human forces, it can adversely affect the organizational commitment of forces due to the shortterm and temporary employment procedure, periodic duties assigned to forces in the health and treatment system, and lack of employed and contracted forces.

In Haji Nabi, Reisi \& Ojagh (2012) study, the mean scores of talent absorption and conservation dimensions 
were lower than average, which complies with our findings. This similarity can be attributed to the similarity between the research populations in both studies. However, the mean score of the talent development dimension was lower than average, which does not comply with our findings. In the research by Haji Nabi et al. the mean score of the choice and use of talents dimensions were higher than average. The lack of compliance between the results can be ascribed to the different questionnaires with more dimensions.

Results of analysis of organizational commitment condition show that the mean score of organizational commitment of working midwives was 101. The affective commitment dimension (with a mean score of 35) had the highest mean, whereas normative commitment (with a mean score of 31) had the lowest mean score.

Results of the study of Saleh, Darawad \& Al-Hussami (2014) showed that the organization commitment and affective commitment scores of nurses working in wards were $103.68 \pm 24.98$ out of 161 and $34.56 \pm 8.74$ out of 56 , respectively. These results comply with the present research results $(101 \pm 20.06$ and $35 \pm 9.56)$. However, levels of organizational commitment in nurses working in ICUs (intensive care units) were lower than ward nurses, which can be attributed to the sensitivity and significance of operations in the intensive care units. Similar to the present study, in the studies by Savaneviciene \& Stankeviciute(2011) and Mokhtari, Roodgarnejad \& Kiakajori (2014), affective commitment and normative commitment had the highest and lowest mean scores, respectively.

In the investigations by Mandegar et al. (2015), Zarei et al. (2016), and Mosadeghrad \& Ferdosi (2013) the normative commitment and continuance commitment dimensions had the highest and lowest scores, respectively, but are not in line with our results. This lack of conformity could be attributed to the level of moral knowledge acquired in families as such knowledge is more valued in smaller cities, while the present research was conducted in Tehran Metropolis.

In general according to the research findings, there was a relationship between talent management and organizational commitment, and this finding is in line with the results reported by Arab Halvaei \& Ejlali (2015).

According to our findings, talent management showed statistically significant relationship with organizational commitment of midwives. Talent management status was higher than average. The mean scores of the talent absorption and conservation dimensions were lower than average, and thus measures should be taken to reform the processes of hiring and absorbing midwives, signing contracts with them, and paying salaries and benefits based on their professional competencies and effectiveness. The average score of talent development dimension was higher than average, and thus improvement of talent management status is owed to this dimension. Talent management can be utilized as an effective strategy for improving organizational commitment of midwives.

Finally, hospital managers can use talent management for improving and increasing midwives' organizational commitment. In this regard, it is recommended that the relationship between talent management with organizational commitment be compared in midwives working in public and private hospitals. Also similar study with larger sample in health centers is done and the results be compared with public and private hospitals results.

Considering the relationship between talent management and organizational commitment, these results can be used for increasing midwives' commitment. With increasing commitment, turnover will decrease and performance and quality of services will increase.

\section{Acknowledgements}

This study is extracted from the master thesis of Nursing and Midwifery School of Iran University of Medical Sciences. The authors hereby express their gratitude to the Research and Higher Education Deputy of Iran University of Medical Sciences and all authorities and midwives working in hospitals affiliated to Iran University of Medical Sciences without whose cooperation and assistance this research could not have been conducted.

\section{Conflict of Interest}

The authors declared no conflict of interests.

\section{References}

Al-Hassan, M. A. 2014. Factors underlying the behavior of Saudi female nurses towards turnover at AL-Iman General Hospital. The Journal of Macro Trends in Health and Medicine, 2(1):233-263.

Aliyu, U., Mathew, O. K., Yayok Paul, R., Shinaba, S. T., Romoke Oyewole, W., \& Olabukun Olusanya, M. 2014. Strategies for recruiting and retaining an effective nursing workforce in $\mathrm{Ni}$ geria. IOSR Journal of Nursing and Health Science, 3(5), pp. 1-11. doi: 10.9790/1959-03520111 
Allen, N. J., \& Meyer, J. P., 1990. The measurement and antecedents of affective, continuance and normative commitment to the organization. Journal of Occupational Psychology, 63(1), pp. 1-18. doi: 10.1111/j.2044-8325.1990.tb00506.x

Amiri, A. N., Jandaghi, G., Akhavan Alavi, S. H., \& Sabokro, M. 2014. Talent development in light of satisfaction and career success. Mitteilungen Klosterneuburg, 64(1), pp. 240-260.

Arabpour, A. R., \& Nikpour, A. 2014. [The Effects of the Aspects of Talent Management on Human Resource Productivity in the Public Organizations in Kerman (Persian)]. Quarterly Research of Human Resource Management, Comprehensive University of Imam Hussein, 7(1), pp. 159-186.

Arab Halvaei, M. \& Ejlali, S. 2015. Surveying relationship of talent management and organizational commitment case study: Kalleh Amol Meat Products Company. Journal of International Education in Business, 3, pp. 77-80.

Collings, D. G., Mcdonnell, A., \& Scullion, H. 2009. Global talent management: The law of the few. Philadelphia: Routledge.

Haji Nabi, K., Reisi, P., \& Ojagh, N. S. 2012. Relationship between talent management and nursing employee performance in hospitals of Karaj city. Health Information Management, 10(7), pp. 964-971.

Muhammad, I. H. \& Shao, Y. 2013. The role of talent management and HR generic strategies for talent retention. African Journal of Business Management, 7(29). pp. 2827-35. doi: $10.5897 /$ ajbm2012.1369

Kheirkhah, M., Akbarpouran, V., \& Haqani, H. 2016. Relationship between talent management and organizational learning in midwives Operating in Iran University of Medical Sciences. Research Journal of Medical Sciences, 10(5), pp. 535-539. doi: 10.3923/rjmsci.2016.536.540

Lesley Onnis, L. A. 2014. Managers are the key to workforce stability: an HRM approach towards improving retention of health professionals in remote northern Australia. Human Resource Management, 6, pp. 1-17.

Mandegar, M., Miri, M. R., Naderi, F., \& Jalayeri, S. 2015. [The relationship of organizational commitment with mental health among employees of Birjand University of Medical Sciences (Persian)]. Scientific Quarterly of Birjand Nursing \& Midwifery Faculty, 12(2), pp. 91-95.

Mokhtari, M., Roodgarnejad, F., \& Kiakajori, K. 2014. [Examine the relationship between organizational commitment and its impact on organizational learning Klantryhay Gilan (Case study: Rasht) (Persian)]. Police Knowlege Quaterly of Guilan, 3(11), pp. 53-62.

Mosadeghrad, A. M., \& Ferdosi, M. 2013. Leadership, job satisfaction and organizational commitment in healthcare sector: proposing and testing a model. Materia Socio Medica, 25(2), pp. 121-26. doi: 10.5455/msm.2013.25.121-126

Mosadeghrad, A. M., Ferlie, E., \& Rosenberg, D. 2008. A study of the relationship between job satisfaction, organizational commitment and turnover intention among hospital employees. Health Services Management Research, 21(4), pp. 211-227. doi: 10.1258/hsmr.2007.007015

Nasr Esfahani, M., Nasr Esfahani, A. \& Noori, A. 2011. [The relationship between servant leadership and organizational commitment and its components in staff welfare organizationa of
Isfahan (Persian)]. Journal of Management Research, 4(11), pp. 105-124.

Nehrir, B., Ebadi, A., Tofighi, S., Karimi Zarchi, A. A., \& Honarvar, H. 2010. Relationship of job satisfaction and organizational commitment in hospital nurses. Journal of Military Medicine, 12(1), pp. 23-26.

Nopasand Asil, S. M., Malek Akhlagh, E., \& Ashegh Hosseini Mehravani, M. 2013. The relationship between talent management and organizational performance. Quartery of Human Resource Mamangement Research, 6(1), pp. 31-51.

Saatchi, M., Kamkari, K., \& Askarian, M. 2010. [Psychological tests (Persian)]. (1 $1^{\text {st }}$ edn). Tehran: Virayesh Publication.

Saleh, A. M., Darawad, M. W., \& Al-Hussami, M. 2014. Organizational commitment and work satisfaction among Jordanian nurses: A comparative study. Life Science Journal, 11(2), pp. 3136.

Salehi Kordabadi, S., \& Rahbari Nia, S. A. 2015. [Talent management and its relationship with emotional intelligence (Case study: Ministry of justice of Guilan Province) (Persian)] Monthly Management and Accounting Journal, 10, pp. 18-26.

Savaneviciene, A. \& Stankeviciute, Z. 2011. [Human resource management practices linkage with organizational commitment and job satisfaction (Persian)]. Economins and Management, 16, pp. 921-928

Tajuddin, D., Ali, R. \& Kamaruddin, B. H. 2014. The need of talent management as a business strategy for Malaysian banking institutions. Australian Journal of Basic and Applied Sciences, 8(5), pp. 69-74.

Taleghani, G. R., Amini, S., Ghaffari, A., \& Adoosi, H. 2013. [The relationship between talent management on the performance of faculty members of Isfahan university (Persian)]. Journal of Public Management, 5(3), pp. 83-102.

Zarei, E., Ahmadi, F., Danshkohan, A., \& Ramezankhani, A. 2016. The correlation between organizational commitment and the quality of working life among staff of Sarpolzahab health network. Journal of Health Promotion Management 5(2), pp. 61-69. 
